\title{
diSPIM Allows Three-dimensional Characterization of Calcium Activity in Intact Islets of Langerhans.
}

\author{
Zeno Lavagnino ${ }^{1}$, David W. Piston ${ }^{1}$ \\ 1. Department of Cell Biology \& Physiology, Washington University School of Medicine, St. Louis, \\ MO, USA
}

Blood glucose homeostasis is required for normal physiology of many living organisms. Within this framework, the islet of Langerhans plays a fundamental role in the regulation of glycemic levels. This micro-organ is $\sim 100 \mu \mathrm{m}$ in diameter and is responsible for the secretion of insulin and its counter regulatory hormone, glucagon. When blood glucose increases above normal levels, insulin is secreted by $\beta$-cells to restore the equilibrium. If blood glucose decreases, then glucagon is secreted by $\alpha$-cells to release glucose stores. Because of the therapeutic success of insulin replacement therapy for the management of diabetes, the majority of islet research has focused on insulin and $\beta$-cells. This has led to a well-characterized consensus model of glucose stimulated insulin secretion, based around membrane depolarization and calcium influx. In recent years, it has become evident that $\alpha$-cells and glucagon dysfunction also contribute to the pathophysiology of diabetes, specifically exacerbating hyperglycemia [1]. There is not yet a consensus model for glucose regulation of glucagon secretion, and intracellular and intercellular mechanisms related to glucagon secretion, including the roles of calcium and cAMP, have not been fully characterized. A major impediment in the study of $\alpha$-cells is a lack of reliable methods to measure the dynamic properties of $\alpha$-cells within the intact islet of Langerhans [2]. A noninvasive, reliable microscopy technique able to provide three-dimensional imaging of the whole intact islet is crucial, since isolated $\alpha$-cells demonstrate different behavior than those within intact islets. Light-sheet microscopy is a powerful tool for fast, 3D imaging of thick scattering samples. More recently, diSPIM [3] was demonstrated to yield isotropic resolution in $\mathrm{x}, \mathrm{y}, \mathrm{z}$ by collecting the information from both sides of the illumination and detection pathways.

To investigate and characterize the calcium activity in whole islet $\alpha$-cells, we used a transgenic which provides a combination of an ultra-sensitive fluorescent protein calcium sensor (GCaMP6) with an improved glucagon-promoter driven Cre recombinase (Glu-iCre). These islets allowed us to measure $\alpha$-cell calcium dynamics with high specificity throughout the whole islet with a diSPIM microscope (ASI imaging). Using two Nikon 40X 0.8 NA objectives we obtained isotropic resolution of $350 \mathrm{~nm}$ in $\mathrm{x}, \mathrm{y}, \mathrm{z}$. The speed of acquisition of the light-sheet fluorescence microscope principle allowed us to obtain entire three dimensional stacks of images throughout the intact islet in less than 5 secs, and the low excitation intensity distributed over the sample resulted in negligible photobleaching over a period of $30 \mathrm{~min}$. To characterize calcium activity of $\alpha$-cells, we used different glucose concentrations and drugs known to trigger a response in terms of glucagon secretion or calcium activity. We used a potent glucagon secretagogue, arginine, to see the response of GCaMP6 intensity over time under low $(1 \mathrm{mM})$ and high $(11 \mathrm{mM})$ glucose conditions. To understand the relationship between ATP-dependent potassium channel activity and calcium we used two well-known drugs that act as an activator (Diazoxide) or a blocker(Tolbutamide) of $\mathrm{K}_{\mathrm{ATP}}$ channels, in both conditions of low and high glucose.

Imaging intact islets of Langerhans from Glucagon-iCre:GCaMP6f mice provides a novel tool for characterizing calcium activity in $\alpha$-cells in response to different stimuli. Cells were treated with 2 concentrations of glucose (low, $1 \mathrm{mM}$ and high, $11 \mathrm{mM}$ ) with different drugs in both conditions, and the calcium activity was measured. These data revealed heterogeneous sets of cell populations in each islet (Table 1 and Figure 1). Secretion experiments were conducted by incubating the islets in the same imaging buffer conditions for $30 \min (\mathrm{n}=3$ mice). 
Arginine generates a potent response in calcium activity and secretion at low glucose, while it shows little increase under high glucose concentrations. The different responses to tolbutamide and diazoxide illustrate the $\alpha$-cell population heterogeneities. Diazoxide, but not Tolbutamide, inhibits glucagon secretion, which suggests a role for the $\mathrm{K}_{\text {АTP }}$ channels at low glucose conditions, but not at high glucose levels, where calcium activity is not suppressed. This lead us to hypothesize that glucose inhibits secretion by a non-calcium-dependent pathway, which may inhibit glucagon vesicle trafficking or exocytosis.

$\alpha$-cells form a heterogeneous population, which can be defined by the types of $\left[\mathrm{Ca}^{2+}\right]_{\mathrm{i}}$ oscillations. Depending on drug and glucose concentrations, calcium activity within the populations show different behaviors. $\alpha$-cell $\left[\mathrm{Ca}^{2+}\right]_{\mathrm{i}}$ appears to be necessary for glucagon secretion, but at high glucose levels, inhibition of glucagon release seems to be unrelated to calcium. The data presented here demonstrate that we can use multicolor diSPIM to image vesicle dynamics and secretion events, and correlate their relationships to calcium and other second messenger activities.

\section{References:}

[1] Reissaus C, \& Piston DW. Diabetes (2017).

[2] Le Marchand S, \& Piston DW. Plos One (2012).

[3] Wu Y et al. Nat. Biotechnology (2013).

\begin{tabular}{|l|l|}
\hline \multicolumn{1}{|c|}{$1 \mathrm{mM}$} & \multicolumn{1}{|c|}{$11 \mathrm{mM}$} \\
\hline Pop $1-15 \pm 8 \%$ cells no activity & Pop $1-63 \pm 12 \%$ cell show no activity \\
\hline $\begin{array}{l}\text { Pop } 2-58 \pm 11 \% \text { cells show short oscillatory } \\
\text { activity }\end{array}$ & Pop $2-37 \pm 23 \%$ cells show activity \\
\hline $\begin{array}{l}\text { Pop } 3-27 \pm 9 \% \text { cells show long oscillatory } \\
\text { activity }\end{array}$ & \\
\hline
\end{tabular}

Table 1. $\alpha$-cells populations in response to low and high glucose concentrations. Data averaged over 80 cells in 10 islets from 3 different mice.
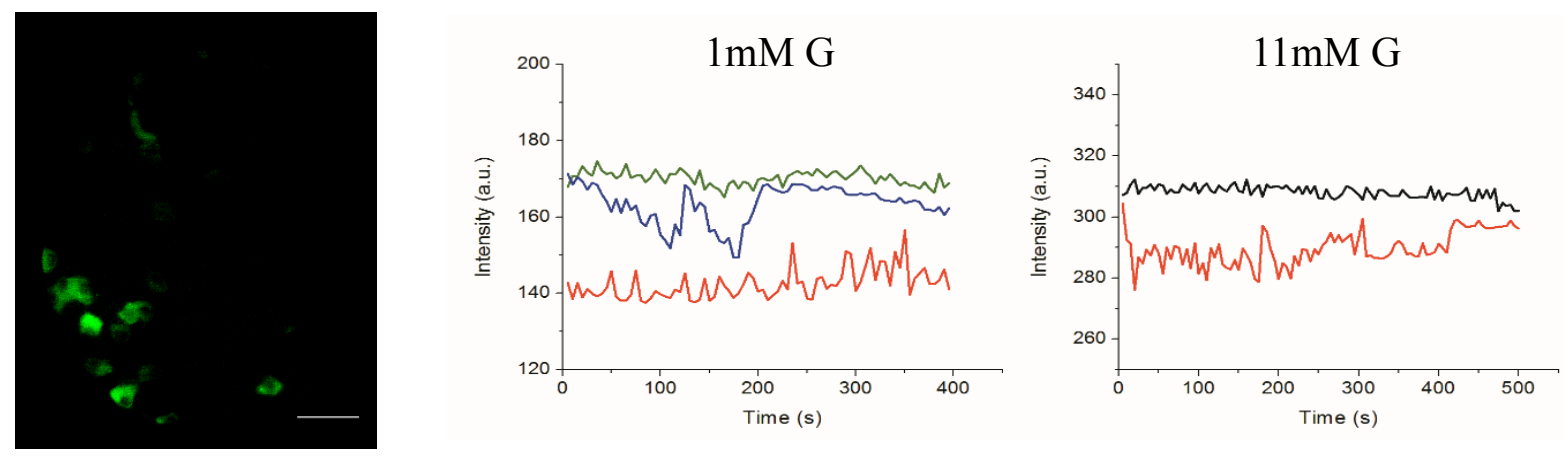

Figure 1. Maximum projection of 30 planes $(\sim 24 \mu \mathrm{m})$ within an intact islet and representative traces of populations of $\alpha$-cells at low and high glucose concentrations. 